\title{
Application of Steering Robot in the Test of Vehicle Dynamic Characteristics
}

\author{
Runqing Guo ${ }^{1, a^{*}}$, Zhaojuan Jiang ${ }^{2, b}$ and Lin Yuan ${ }^{3, c}$ \\ No.68, East Xianfeng Road, China Automotive Technology and Research Center \\ Dongli District, Tianjin, P.R.China \\ aguorunqing@catarc.ac.cn, bjiangzhaojuan@catarc.ac.cn, cyuanlin@catarc.ac.cn
}

\begin{abstract}
Keywords: active safety; Steering Robot; ISO standards; handling and stability
Abstract. The dynamic behaviour of a road vehicle is a very important aspect of active vehicle safety. Steering Robot is applied in the test of vehicle lateral transient response and on-centre handling. Instead of manual operation, Steering Robot makes complicated steering input conduct accurately and repeatedly, which fulfill requirements of standards effectively. Application of Steering Robot, ISO 7401 and ISO 13674 are implemented to assess vehicle handling and stability without human's interfering.
\end{abstract}

\section{Introduction}

The primary object of ISO 7401 tests is to determine the transient response behaviour of a vehicle. Several test methods for obtaining transient response characteristics in the domains of time and frequency are provided, such as step input, sinusoidal input (one period), random input, pulse input and continuous sinusoidal input. Each of them relies on exquisite steering input which people hardly accomplish repeatedly. In addition, ISO 13674 defines two tests with strict steering wheel input style.

Steering robot is introduced to establish a complete set of road test system for ISO regulations on vehicle dynamic behaviour test by China automotive technology and research center, a Chinese leading automobile detection mechanism[1]. The paper analyzes test requirements of the two standards above and corresponding evaluation methods on passenger vehicle dynamic performance. And test data is processed and analyzed according to ISO standards using self-developed software. In the paper, a specific domestic vehicle test results are presented which shows steering robot provides accurate steering wheel movement defined in standards.

\section{Requirements of ISO 7401 and ISO 13674 [2-8]}

Requirements of ISO 7401. Characteristic values and functions in the time and frequency domains are considered necessary for characterizing vehicle transient response in ISO 7401. Test methods such as step input and sinusoidal input (one period) of time domain and pulse input of frequency domain are conducted based on strict steering wheel manoeuvres with high start speed of $100 \pm 2 \mathrm{~km} / \mathrm{h}$ in the kerb and laden mass condition. In step input test, a preselected steering input value is applied as rapidly as possible and maintained at that value for several seconds. Besides, the time between $10 \%$ and $90 \%$ of the steering input should not be greater than $0.15 \mathrm{~s}$. In one period Sinusoidal input test, one full period sinusoidal steering-wheel input with a frequency of $0.5 \mathrm{~Hz}$ is applied, and the amplitude error between the actual and the true sine wave shall be less than $5 \%$ of the first peak value. In pulse test, a pulse width of $0.3 \mathrm{~s}$ to $0.5 \mathrm{~s}$ is used. In addition, the steering-wheel input should be up to a magnitude sufficient to produce the desired lateral acceleration in the three tests above. The standard lateral acceleration level is $4 \mathrm{~m} / \mathrm{s} 2$. Requirements of ISO 7401 show that it is necessary to introduce steering robot to fulfill the strict steering input in vehicle transient response tests.

The time histories of variables used for data evaluation shall be plotted and then related characteristic values are calculated from fitting curves. In frequency domain, a Fourier analysis shall be made of the steering-wheel angle time history. For each pair of input and output variables, the frequency response (i.e. gain and phase-angle functions) shall be presented on a graph. 
Requirements of ISO 13674. ISO 13674 consists of two parts, weave test and transition test. The weave test is an open-loop procedure with test velocity of $100 \mathrm{~km} / \mathrm{h}$ and requires the steering-wheel to be subjected to an oscillatory input. The preferred steering input waveform is nominally sinusoidal and its frequency is defined as $0.2 \mathrm{~Hz} \pm 10 \%$. Besides, the amplitude of the steering input shall be sufficient to produce the required peak value of vehicle lateral acceleration $\pm 10 \%$. The standard peak value is $2 \mathrm{~m} / \mathrm{s} 2$. A minimum of four consistent cycles of steering input and of vehicle response are required for subsequent data analysis. According to requirements of steering input and vehicle response level, a steering robot can offer enhanced consistency of steering input and hence of test data, and fewer test cycles can be allowed as described in ISO 13674-1. In ISO 13674-2, the steering-wheel shall be subjected to a ramp input with a nominally constant angular velocity. And the steering input is required to be applied for a minimum duration of 3 seconds, and at an angular velocity not exceeding 5 degrees/second, until the lateral acceleration achieved by the vehicle reaches a minimum of $1.5 \mathrm{~m} / \mathrm{s} 2$. The test shall be performed a sufficient number of times in each turn direction using the same steer input profile, which is hardly made manually.

\section{Application of Steering Robot}

The steering robot is integrated in a road test system to make steering wheel move as defined in ISO 7401 and 13674. Illustrative diagram of the system is as shown in Fig. 1. When the steering robot provides accurate and coincident wheel movements, steering angle and torque are monitored by itself. Besides, variables like vehicle attitude angle, angular rate, acceleration and speed are acquired by inertial gyro. These measured variables are transmitted to the multichannel data acquisition unit through analog channels and can be sent to the tablet computer installed with the software for data post-processing by Ethernet cable. Therefore, the road test system is established base on steering robot.

The steering robot consists of a steering wheel with integral servo-motor that either replaces, or attaches to, the standard steering wheel normally fitted to the vehicle. And it has built-in transducers to measure the angular position of the steering wheel and the torque being applied to it by the motor, which is computer-controlled. The installation of steering robot on a testing vehicle is as shown in Fig. 2 .

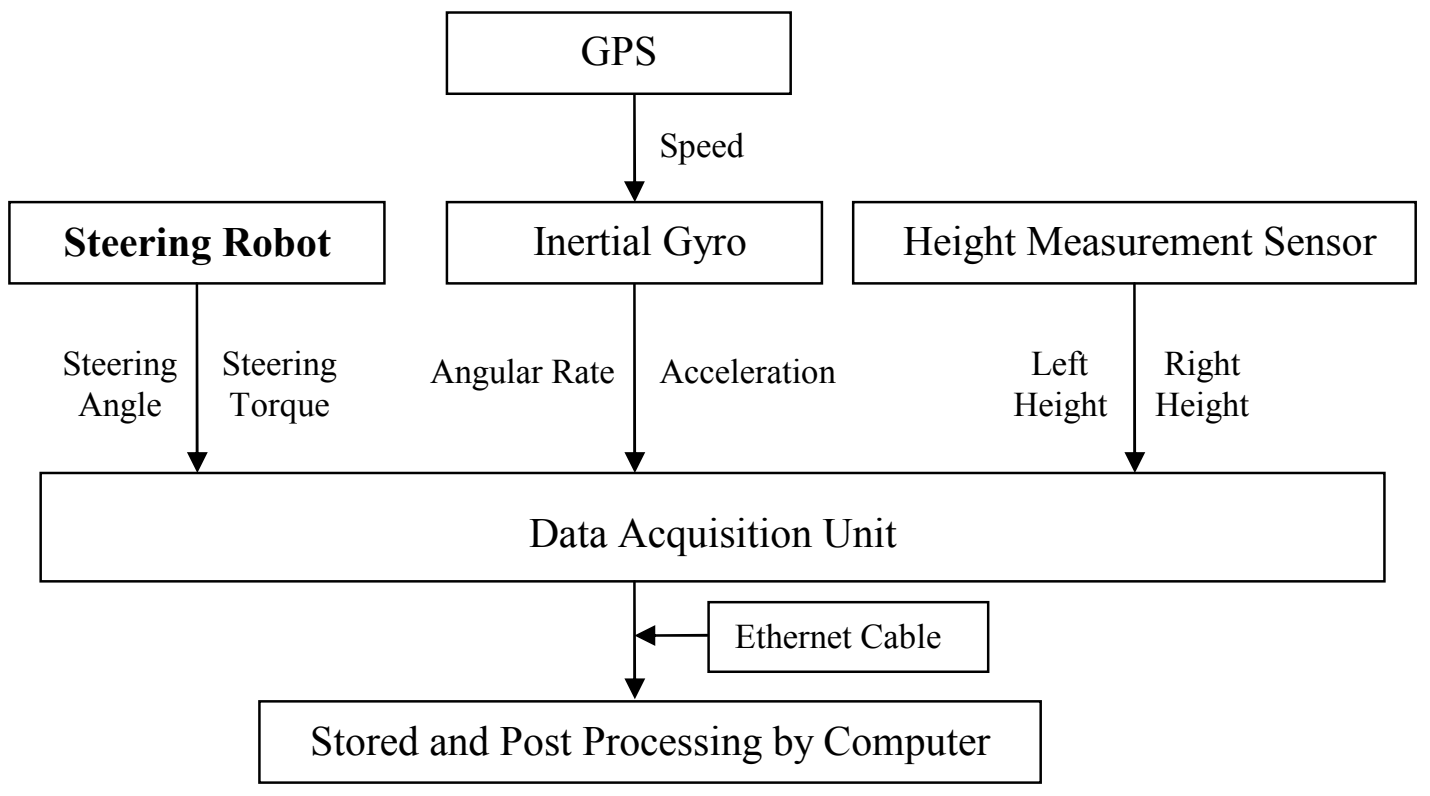

Figure 1 Illustrative diagram of the testing system using steering robot 


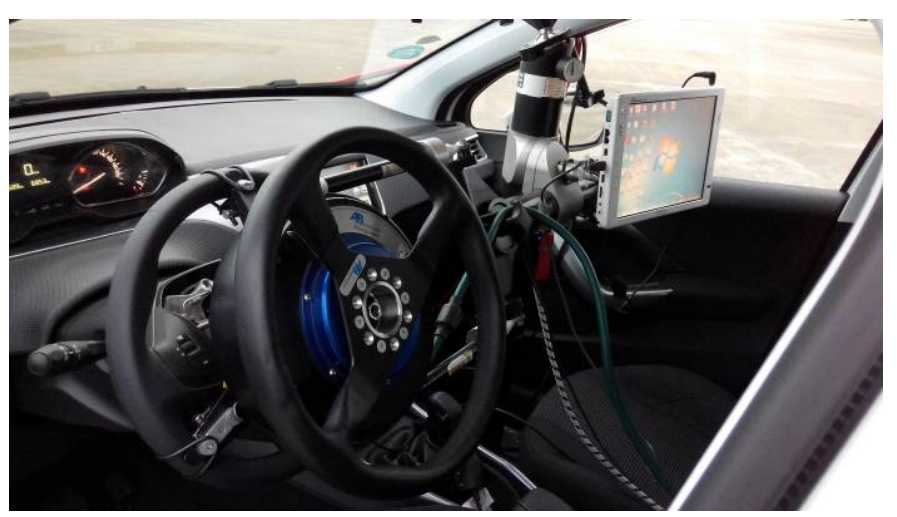

Figure 2 Installation of Steering Robot

\section{Vehicle Field Test Using Steering Robot}

Based on the testing system above, vehicle field tests are conducted abiding by ISO 7401 and ISO 13674 at proving ground.

Test Presentation of ISO 7401[2]. Fig. 3 shows variable curves of step input test. From steering angle time curve, it's seen that steering wheel angle is subjected from zero to step peak value 40deg in a very short time and maintained for about $4.5 \mathrm{~s}$. And the procedure is controlled by the steering robot accurately, which makes the vehicle lateral acceleration level achieve about $4.0 \mathrm{~m} / \mathrm{s} 2$. Based on variable curves plotted, response parameter data are calculated and summed in Table 1 using self-developed software. Normally, Vehicle stability is higher when steady state yaw rate response gain is smaller, and yaw rate and lateral acceleration response time means the vehicle response speed which represents the vehicle handling performance.
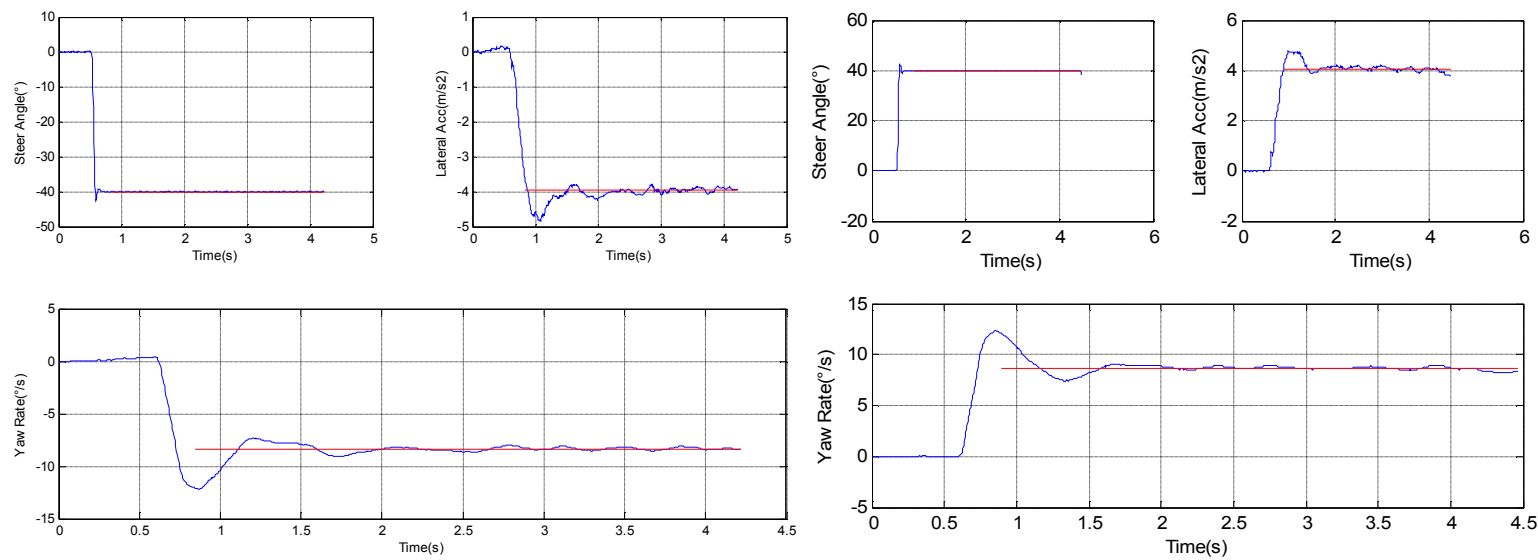

Left turn

Figure 3 Step input test

Right turn

Table 1 Step input-Response data summary

\begin{tabular}{|c|c|c|c|c|c|}
\hline Parameter & Symbol & Unit & Left turn & Right turn & Average \\
\hline Steady state yaw rate response gain & $(\psi / \delta \mathrm{H}) \mathrm{ss}$ & s-1 & 0.209 & 0.216 & 0.213 \\
\hline Lateral acceleration response time & Tay & $\mathrm{S}$ & 0.256 & 0.266 & 0.261 \\
\hline Yaw rate response time & $\mathrm{T} \psi$ & S & 0.157 & 0.164 & 0.161 \\
\hline Lateral response peak response time & Tay max & $\mathrm{S}$ & 0.479 & 0.424 & 0.452 \\
\hline Yaw velocity peak response time & T $\psi$ MAX & $\mathrm{S}$ & 0.285 & 0.285 & 0.285 \\
\hline Overshoot value of lateral acceleration & Uay & - & 0.223 & 0.178 & 0.201 \\
\hline Overshoot value of yaw velocity & $\mathrm{U} \psi$ & - & 0.459 & 0.429 & 0.444 \\
\hline
\end{tabular}


In sinusoidal input -one period test, the steering robot provides sinusoidal input with one period 2.0 second and the input peak value is set $38 \mathrm{deg}$ which produces nearly standard lateral acceleration $4.0 \mathrm{~m} / \mathrm{s} 2$ as shown in Fig. 4. Once sinusoidal input is given, yaw rate and lateral acceleration are produced successively. The time lag means the speed that vehicle responds to steering input. And lateral acceleration and yaw velocity gain are inverse ratio with vehicle stability performance. All the values of the testing vehicle are reasonable and given in Table 2.
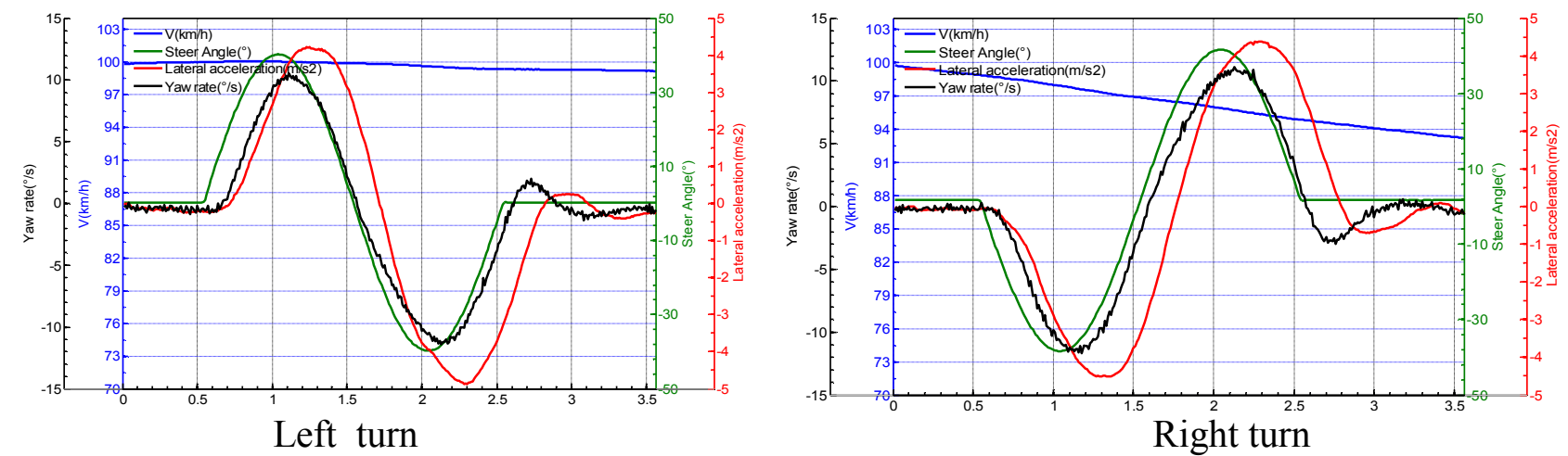

Figure 4 Sinusoidal input (one period) -Time histories

Table 2 Sinusoidal input (one period) -Response data summary

\begin{tabular}{|c|c|c|c|c|c|}
\hline \multicolumn{6}{|c|}{ sinusoidal input (one period)-response data summary-Laden } \\
\hline \multirow[b]{2}{*}{ Parameter } & \multirow[b]{2}{*}{ Unit } & \multicolumn{2}{|c|}{ Left turn } & \multicolumn{2}{|c|}{ Right turn } \\
\hline & & $\begin{array}{l}\text { mean } \\
\text { value }\end{array}$ & $\begin{array}{l}\text { Standard } \\
\text { deviation }\end{array}$ & $\begin{array}{l}\text { mean } \\
\text { value }\end{array}$ & $\begin{array}{c}\text { standard } \\
\text { deviation }\end{array}$ \\
\hline \multicolumn{6}{|c|}{ time lag between steering wheel angle and lateral acceleration } \\
\hline peak 1 & $\mathrm{~ms}$ & 266.7 & 41.097 & 260 & 21.602 \\
\hline peak 2 & $\mathrm{~ms}$ & 263.3 & 30.912 & 263.3 & 16.997 \\
\hline \multicolumn{6}{|c|}{ time lag between steering wheel angle and yaw velocity } \\
\hline peak 1 & $\mathrm{~ms}$ & 90 & 45.461 & 103.3 & 4.714 \\
\hline peak 2 & $\mathrm{~ms}$ & 100 & 21.602 & 80 & 43.205 \\
\hline $\begin{array}{l}\text { Lateral } \\
\text { acceleration gain }\end{array}$ & $\mathrm{g} / \mathrm{deg}$ & 0.01197 & $6.9787 \mathrm{E}-05$ & 0.01145 & $3.56 \mathrm{E}-05$ \\
\hline yaw velocity gain & s-1 & 0.3043 & $2.7195 \mathrm{E}-04$ & 0.2854 & $4.301 \mathrm{E}-03$ \\
\hline
\end{tabular}

In frequency domain, the pulse test is presented in paper. Its steering input profile manoeuvred by the robot is as shown in Fig. 5. The pulse width is set $0.5 \mathrm{~s}$ and its peak value is $70 \mathrm{deg}$ which produces the desired lateral acceleration $4.0 \mathrm{~m} / \mathrm{s} 2$. The frequency response of yaw velocity related to steering wheel angle is analysed by fourier transform. And then the gain and phase-angle functions defined in frequency less than $3.0 \mathrm{~Hz}$ are plotted as shown in Fig. 6 . The gain peak value appears nearly at the frequency of $1.0 \mathrm{~Hz}$ in both left and right turn test, which explains that the testing vehicle responds most seriously to the steering input signal of $1.0 \mathrm{~Hz}$. The phase angle increases along with frequency growth, which illustrates that the steering input of higher frequency brings bigger time lag between steering input and vehicle response. 


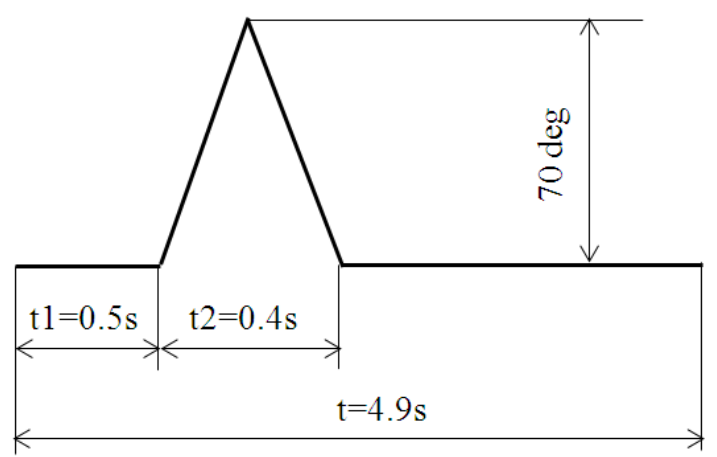

Figure 5 The pulse input profile

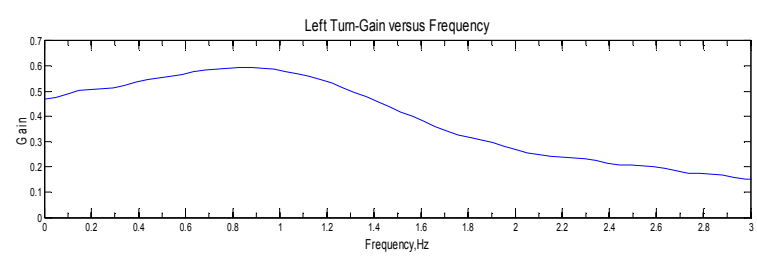

Left Tum-Phase angle versus Frequency

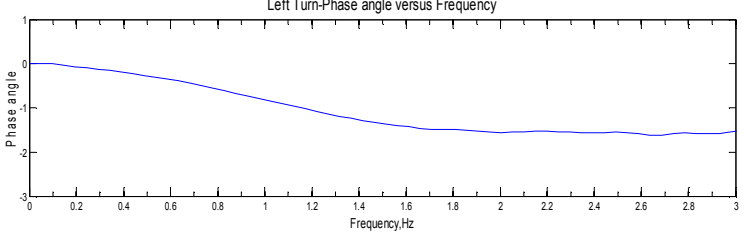

Left turn

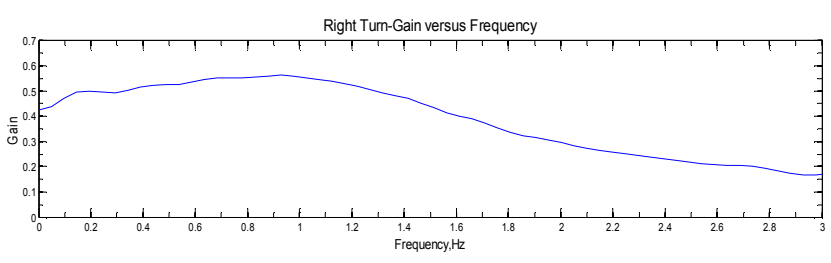

Right Turn-Phase angle versus Frequency

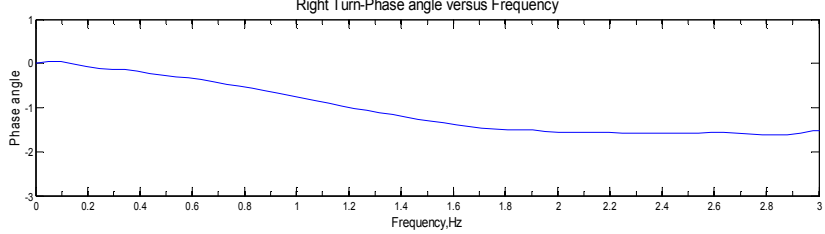

Right turn

Figure 6 The pulse input frequency response

Test Presentation of ISO 13674[3,4,9,10,11]. In paper, a wave test of ISO 13674-1 is presented to show advantages of steering robot for the test results. Four consistent cycles of steering input and of vehicle response are selected for subsequent data analysis. Fig. 7 shows four test cycles input by the steering robot and vehicle response, lateral acceleration. It's seen that four cycles of steering input made by the robot is completely consistent so that only four wave tests are conducted in the procedure. Besides, the peak values of four lateral acceleration cycles reaches standard value, $2.0 \mathrm{~m} / \mathrm{s} 2$
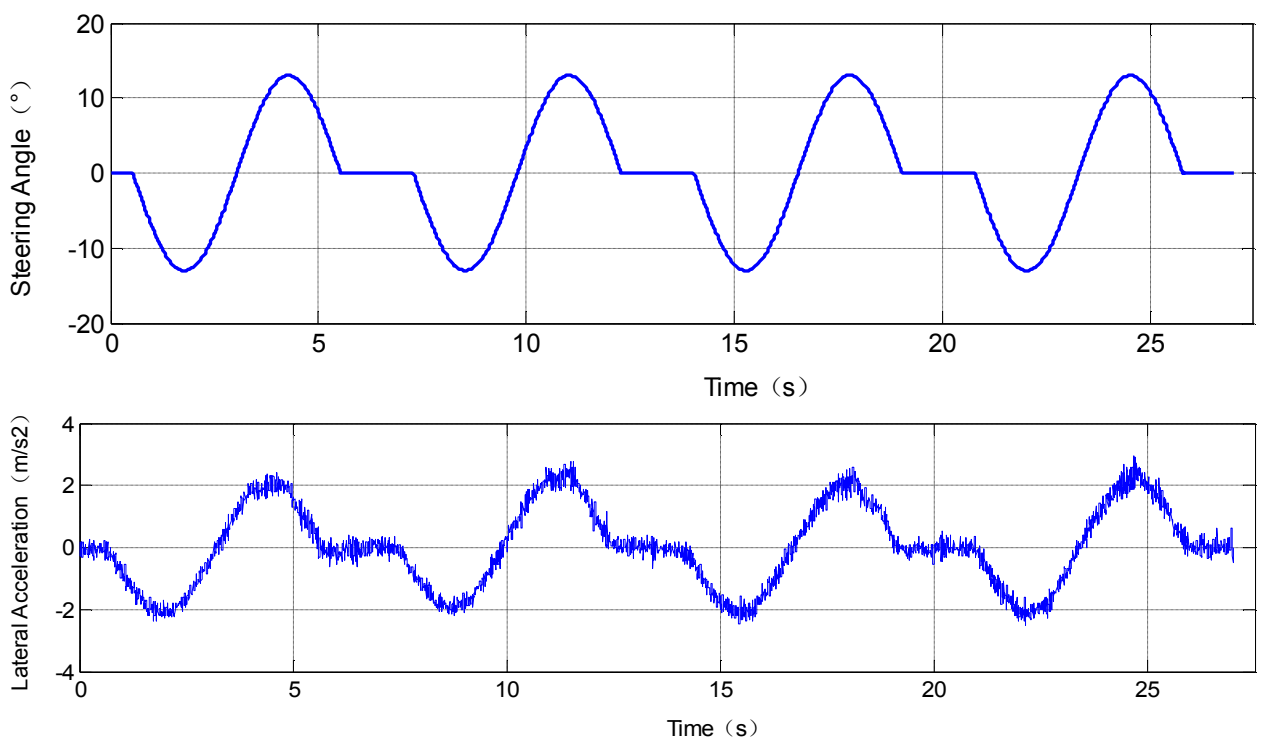

Figure 7 Four cycles of wave input by steering robot and its response

The recorded variables are taken in pairs and plotted one against the other on Cartesian co-ordinates as shown in Fig. 8. For each pair of variables, this produces a series of hysteresis loops 
laid one over another, the number of loops corresponding to the number of data cycles analysed. In Fig. 8 , abscissa range determined by the two solid lines is the range of polynomial curve fit for evaluating characteristics.
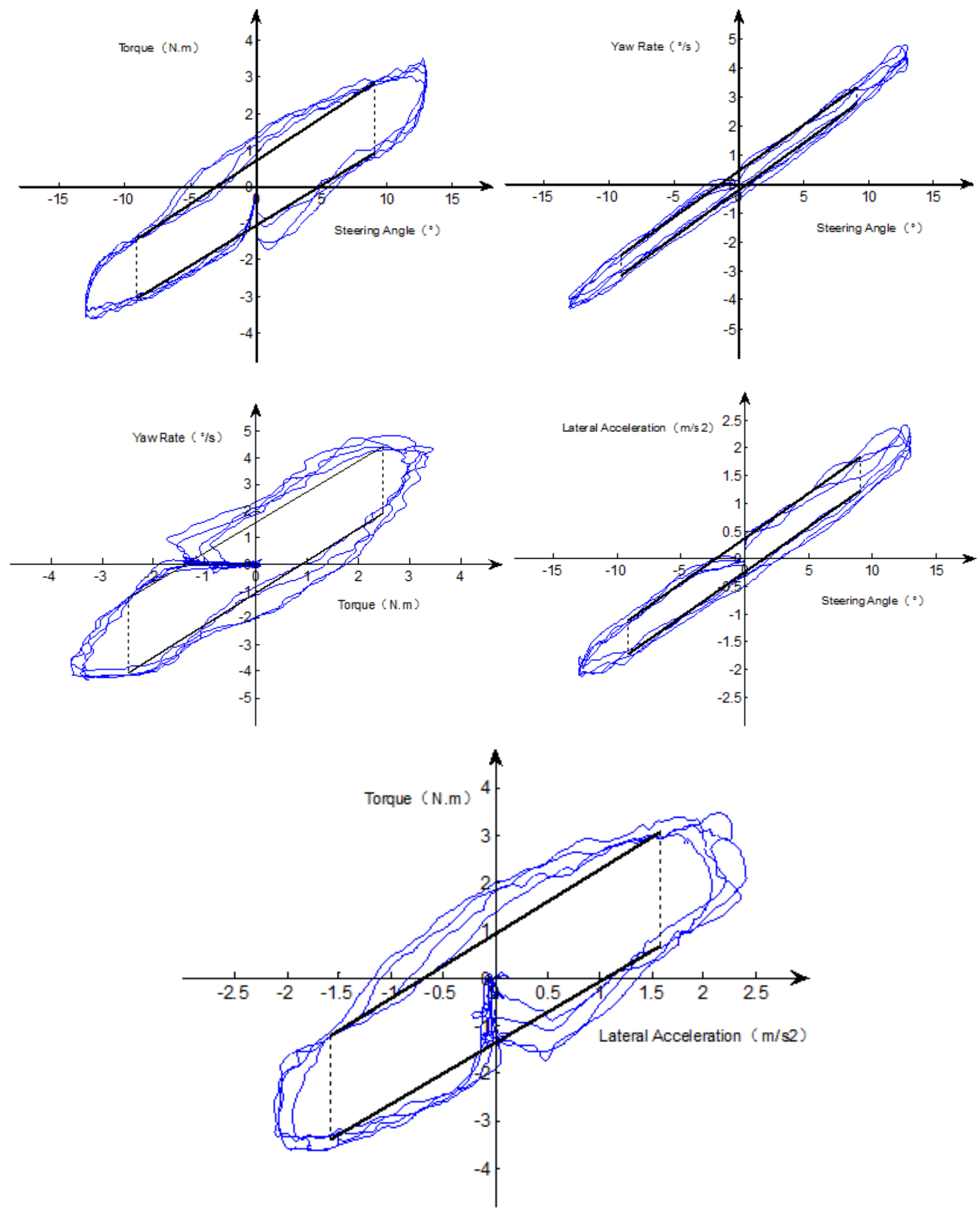

Figure 8 Hysteresis loops of variables

Application of steering robot reduces the testing times and remarkably promotes testing efficiency 
and consistency, which makes hysteresis loops reasonable and characteristics evaluated accurate and believable. From the polynomial curve fits to the combined hysteresis loops in Fig. 8, many characteristics required in ISO 13674 for the quantification of vehicle on-centre handling are evaluated as shown in Tabel 3 . These characteristics can be analyzed and contrasted with those of the standard car so that vehicle on-centre handling performance level is obtained.

Tabel 3 Characteristics for the vehicle on-centre handling

\begin{tabular}{|l|l|l|l|}
\hline Parameters & Value & Parameters & Value \\
\hline Steering stiffness $\left(\mathrm{Nm} /{ }^{\circ}\right)$ & 0.22666 & Lateral acceleration deadband & 0.6125 \\
\hline Steering stiffness at zero steer & 0.2206 & Angle deadband $\left({ }^{\circ}\right)$ & 3.7601 \\
\hline Steering friction $(\mathrm{Nm})$ & 1.7727 & Steering hysteresis $\left(^{\circ}\right)$ & 4.0831 \\
\hline Angle hysteresis $\left({ }^{\circ}\right)$ & 7.8862 & Torque at $0 \mathrm{~m} / \mathrm{s} 2(\mathrm{Nm})$ & $2.002 /-1.902$ \\
\hline Yaw velocity response gain $(1 / \mathrm{s})$ & 0.3214 & Torque at $1 \mathrm{~m} / \mathrm{s} 2(\mathrm{Nm})$ & $2.654 /-0.399$ \\
\hline Yaw velocity time delay $(\mathrm{s})$ & 0.15 & Lateral acceleration at $0 \mathrm{~N} . \mathrm{m}$ & $-1.104 / 1.258$ \\
\hline Response deadband $(\mathrm{Nm})$ & 2.2604 & Torque gradient at $0 \mathrm{~m} / \mathrm{s} 2$ & 1.4154 \\
\hline Steering sensitivity $\left(\mathrm{m} / \mathrm{s} 2 /{ }^{\circ}\right)$ & 0.3694 & Torque gradient at $1 \mathrm{~m} / \mathrm{s} 2$ & 0.90791 \\
\hline Minimum steering sensitivity & 0.1629 & Torque hysteresis $(\mathrm{Nm})$ & 2.265 \\
\hline Steering sensitivity at $1 \mathrm{~m} / \mathrm{s} 2$ & 0.6132 & Lateral acceleration hysteresis & 2.0192 \\
\hline
\end{tabular}

\section{Conclusions}

1. The dynamic behaviour of a road vehicle is a very important aspect of active vehicle safety. The testing system integrated with steering robot can fulfill dynamic tests of strict steering input that hardly is provided manually.

2. The steering robot manoeuvres steering wheel as required in ISO 7401 and ISO 13674 with high accuracy and consistency, which cuts down testing expenses and promotes evaluation reliability of testing data.

3. Application of Steering Robot, ISO 7401 and ISO 13674 are implemented to assess vehicle handling and stability in vehicle field tests without human's interfering.

\section{References}

1. Runqing Guo, Lin Yuan and Jinzhong Xie, Implement of Handling and Stability Road Test of Passenger Vehicle for ISO Standards, Applied Mechanics and Materials. 568-570(2014): 1869-1874.

2. ISO 7401-2011: Road vehicles -Lateral transient response test methods-Open-loop test methods.

3. ISO 13674-1-2010: Road vehicles-Test method for the quantification of on-centre handling -Part 1 :Weave test

4. ISO 13674-2-2006: Road vehicles-Test method for the quantification of on-centre handling-Part 2:Transition test

5. ISO 3833:1977, Road vehicles-Types-Terms and definitions.

6. ISO 8855:1991, Road vehicles-Vehicle dynamics and road-holding ability-Vocabulary.

7. ISO 15037-1:1998, Road vehicles-Vehicle dynamics test methods-Part 1: General conditions for passenger cars.

8. ISO/TS 20119, Road vehicles-Test method for the quantification of on-centre handlingDetermination of dispersion metrics for straight-line driving

9. SAE 840069, Objective Evaluation of On-Center Handling Performance

10. SAE 930827, An Objective Measurement Technique for the Quantification of On-Center Handling Quality 
11. SOMMERVILLE, J., FARRER, D.G., WHITEHEAD, J.P. Improvements in the Quantification of On-Center Handling Quality. IMechE C466/049/93J. 